\title{
Neuropsychiatric syndromes of multiple sclerosis
}

\author{
Ruth Murphy, ${ }^{1}$ Stefani O'Donoghue, ${ }_{1}^{2}$ Timothy Counihan, ${ }^{3}$ Colm McDonald, ${ }^{2}$ \\ Peter A Calabresi, ${ }^{4}$ Mohammed AS Ahmed ${ }_{1}^{5}$ Adam Kaplin, ${ }^{4}$ Brian Hallahan ${ }^{2}$
}

\begin{abstract}
'Department of Psychiatry, University College Hospital Galway, Galway, Ireland 2Department of Psychiatry, National University of Ireland, Galway, Ireland

${ }^{3}$ Department of Neurology, National University of Ireland, Galway, Ireland ${ }^{4}$ Department of Neurology, Johns Hopkins University, Baltimore, Maryland, USA ${ }^{5}$ Departments of Medical Education and Psychiatry, Hamad Medical Corporation, Doha, Qatar
\end{abstract}

\section{Correspondence to}

Brian Hallahan, Department of Psychiatry, National University of Ireland, NUI Galway, Galway, Ireland; brian.hallahan@ nuigalway.ie

Received 29 November 2016 Revised 6 February 2017 Accepted 9 February 2017

Published Online First 20 February 2017

\section{CrossMark}

\section{To cite: Murphy $R$} O'Donoghue S, Counihan T, et al. I Neurol Neurosurg Psychiatry 2017;88:697-708.

\section{ABSTRACT}

Neuropsychiatric signs and symptoms occur frequently in individuals with multiple sclerosis (MS), either as the initial presenting complaint prior to a definitive neurological diagnosis or more commonly with disease progression. However, the pathogenesis of these comorbid conditions remains unclear and it remains difficult to accurately elucidate if neuropsychiatric symptoms or conditions are indicators of MS illness severity. Furthermore, both the disease process and the treatments of MS can adversely impact an individual's mental health. In this review, we discuss the common neuropsychiatric syndromes that occur in MS and describe the clinical symptoms, aetiology, neuroimaging findings and management strategies for these conditions.

\section{INTRODUCTION}

Neuropsychiatric abnormalities are diverse, are reported in up to $60 \%$ of patients with multiple sclerosis (MS) and are among the main contributors to the morbidity and mortality associated with MS. ${ }^{1}$ Although psychiatric abnormalities generally present subsequent to neurological diagnosis, the first clinical presentation of MS has been reported to include concomitant psychiatric and neurological symptoms $(2.3 \%)$ or consist of solely psychiatric symptoms $(0.2 \%-2 \%) .^{23}$ Neuropsychiatric conditions encountered include disorders of affect and behaviour, and psychotic and anxiety disorders. Although psychiatric comorbidity can be difficult to diagnose, it is generally responsive to treatment, conferring benefits in functional status, quality of life and overall disease burden. In this review, we discuss the common neuropsychiatric syndromes (psychiatric disorders occurring in the context of the neurological disorder MS) that occur in MS and describe the clinical symptoms, aetiology, neuroimaging findings and management strategies for these conditions. A comprehensive bibliographic search of articles examining neuropsychiatric syndromes (major depressive disorder (MDD), bipolar affective disorder (BPAD), psychosis, anxiety disorders, psychoactive substance misuse, pseudobulbar affect (PBA), euphoria) that occur in MS from the Medline, PsycINFO and Scopus databases was conducted.

\section{MAJOR DEPRESSIVE DISORDER}

MDD is the most common psychiatric disorder associated with MS, with an estimated annual prevalence rate of $15 \%$ and rates of up to $25 \%$ reported in people aged 18-45 years, which is approximately five times the rate observed in the general population. ${ }^{4}$ Almost $50 \%$ of all patients with MS will experience a clinically significant depressive episode following the onset of MS during their lifetime. ${ }^{56}$ Such episodes are often under-recognised and undertreated. ${ }^{178}$ One reason for this lack of detection of MDD is that typical biological symptoms including fatigue, anorexia, poor concentration, memory deficits and insomnia can be present in the absence of MDD in individuals with active MS. Furthermore, typical depressive symptoms including apathy, social withdrawal, feelings of worthlessness, guilt and poor self-esteem are less common than symptoms of frustration or irritability in individuals with MS and comorbid MDD. ${ }^{6}$ Those symptoms which may more accurately indicate a comorbid depressive episode include a pervasive low mood, anhedonia, diurnal mood variation, suicidal ideation, pessimistic or negative patterns of thinking and impaired functionality unrelated to or out of proportion to one's physical disability (table 1). ${ }^{9}$

Suicide is a significant cause of mortality with a $3 \%$ rate of completed suicide in individuals with MS, ${ }^{10}$ which is approximately 7.5 times higher than that of the general population and significantly higher than that reported in individuals experiencing other neurological or chronic medical disease disorders. ${ }^{411-13}$ The presence of suicidal ideation with intent has been reported to be as high as $29 \%$, with depressive symptoms proposed as the most important factor associated with suicidal ideation. ${ }^{14}$ Additional risk factors for parasuicide include male gender, young age at onset of illness, the initial 5 years following diagnosis, current or previous history of depression or deliberate selfharm, social isolation, recent functional deterioration and illicit substance misuse..$^{914}$

The association of MS with MDD including the impact of MS disease activity, severity and duration remains complicated with some studies reporting no relationship between MDD and these indices of MS illness, ${ }^{15-19}$ while others have demonstrated an association between MDD and MS duration ${ }^{20}$ and disease progression. ${ }^{2122}$ This association is complex, with depressive episodes proposed as a possible consequence of the MS neuropathological process itself and/or reaction to the associated psychosocial stress of being diagnosed with MS. ${ }^{23}{ }^{24}$ A genetic predisposition for MDD in individuals with MS is unlikely, as increased incidence rates of depression among first-degree relatives of depressed patients with MS have not been reported. ${ }^{10}$

Aetiological factors implicated with comorbid MDD include hypothalamic-pituitary-adrenal axis dysfunction, medications used in the treatment of 


\begin{tabular}{|c|c|c|}
\hline $\begin{array}{l}\text { Neuropsychiatric } \\
\text { disorder }\end{array}$ & Principal presenting symptoms & Treatment \\
\hline Depression & $\begin{array}{l}\text { Pervasive low mood } \\
\text { Diurnal mood variation } \\
\text { Fatigue } \\
\text { Functional change } \\
\text { Pessimism/negative thinking patterns } \\
\text { latrogenic depressive symptoms secondary to use of corticosteroids, baclofen, } \\
\text { dantrolene and tizanidine }\end{array}$ & $\begin{array}{l}\text { SSRIs are first line (fluoxetine, sertraline) } \\
\text { TCAs—desipramine } \\
\text { SNRIs especially if comorbid pain (venlafaxine, duloxetine) } \\
\text { Mirtazapine (less sexual dysfunction) } \\
\text { Psychotherapy—CBT, supportive, mindfulness, IPT, exercise and } \\
\text { relaxation techniques } \\
\text { Lithium augmentation (diuresis and polyuria may be issues) } \\
\text { ECT for treatment-resistant cases but may increase risk of MS } \\
\text { relapse }\end{array}$ \\
\hline Bipolar disorder & $\begin{array}{l}\text { Elated mood } \\
\text { Increased energy } \\
\text { Talkativeness } \\
\text { Overfamiliarity } \\
\text { Psychomotor agitation } \\
\text { Disinhibition } \\
\text { - Impulsivity } \\
\text { Insomnia }\end{array}$ & $\begin{array}{l}\text { Lithium (risk of diuresis) } \\
\text { Sodium valproate } \\
\text { mania with psychotic symptoms—risperidone, quetiapine, } \\
\text { olanzapine, ziprasidone } \\
\text { If steroid-induced mania, consider lithium, phenytoin, olanzapine } \\
\text { and/or reduced dose of steroids }\end{array}$ \\
\hline Psychosis & $\begin{array}{l}\text { Hallucinations and delusions } \\
\text { Irritability and agitation } \\
\text { Sleep disturbance and grandiosity } \\
\text { Blunted affect, flight of ideas, depression, reduced self-care and pressured } \\
\text { speech } \\
\text { More complex delusions occasionally (erotomanic, nihilistic and } \\
\text { misidentification) }\end{array}$ & $\begin{array}{l}\text { Atypical antipsychotics } \\
\text { Risperidone } \\
\text { Clozapine } \\
\text { Aripiprazole } \\
\text { Quetiapine } \\
\text { Typical antipsychotics (ie, chlorpromazine may worsen balance) } \\
\text { Benzodiazepines (may help sedation but may worsen cognitive } \\
\text { impairment) }\end{array}$ \\
\hline Anxiety disorders & $\begin{array}{l}\text { GAD } \\
\text { Panic disorder } \\
\text { OCD } \\
\text { Social anxiety disorder } \\
\text { Anxiety sympto phobia (self-injection anxiety) }\end{array}$ & $\begin{array}{l}\text { SSRIs are first-line agents } \\
\text { Other options include } \\
\text { Venlafaxine } \\
\text { Buspirone } \\
\text { Pregabalin } \\
\text { Gabapentin } \\
\text { Beta-blockers } \\
\text { Benzodiazepines (short-term only) }\end{array}$ \\
\hline $\begin{array}{l}\text { Pseudobulbar } \\
\text { affect and euphoria }\end{array}$ & $\begin{array}{l}\text { Incongruent emotional expression in response to a non-specific stimulus } \\
\text { Emotions (laughing/crying) disproportionate to the underlying emotional } \\
\text { experience } \\
\text { Absence of voluntary control of facial expression }\end{array}$ & $\begin{array}{l}\text { TCAs (amitriptyline, desipramine, nortriptyline) } \\
\text { SSRIs } \\
\text { Levodopa } \\
\text { Amantadine } \\
\text { Dextromethorphan and quinidine }\end{array}$ \\
\hline
\end{tabular}

B-FS, Beck Fast Screen for Depression in Medically III Patients; CBT, cognitive behavioural therapy; CNS-LS, Center for Neurologic Study-Lability Scale; GAD, generalized anxiety disorder; HADS, Hospital Anxiety and Depression Scale; IPT, interpersonal therapy; MS, multiple sclerosis; NARI, noradrenaline reuptake inhibitor; NaSSA, noradrenergic and specific serotonergic antidepressant; NMDA, N-Methyl-D-aspartate; SNRI, serotonin noradrenergic reuptake inhibitor; SSRI, selective serotonin reuptake inhibitor; TCA, tricyclic antidepressant.

MS and regional brain pathology. Fifty per cent of individuals with MS and comorbid MDD have been found to have reduced suppression of cortisol when administered the dexamethasone suppression test, ${ }^{22}$ a finding frequently replicated in MDD alone. ${ }^{25}$ Furthermore, failure of cortisol suppression has been associated with increased numbers of gadolinium-enhancing lesions. ${ }^{26}$ Psychosocial stressors implicated in MDD include lower socioeconomic status, limited social support, inadequate coping and adjustment mechanisms, unpredictable disease course, loss of recreational activities, severe physical disability and perceived physical incapacity. ${ }^{11}$ Moreover, hopelessness together with uncertainty around prognosis has been demonstrated to lead to irritability and frustration and has been associated with depressive symptoms and suicidal ideation. ${ }^{23} 27$
Following the introduction of interferon beta as a disease-modifying therapy (DMT) in the early 1990s, concern was raised in relation to a putative association between such treatments and the development of depressive symptoms and suicidal ideation. ${ }^{28}$ However, subsequent studies have failed to confirm an association. ${ }^{29-31}$ Nevertheless, common clinical practice post beta-interferon treatment frequently comprises psychoeducation of individuals regarding the risk of interferon-induced depressive symptoms, with the use of prophylactic treatment to be considered in high-risk individuals. ${ }^{2}$ Corticosteroids in particular, but also other treatments used in the symptomatic management of MS including baclofen, dantrolene and tizanidine, have been associated with an increased risk of MDD both with their use and their abrupt discontinuation. ${ }^{32}$ 
In relation to brain pathology in MS and its aetiological association with MDD, MRI studies to date have reported variable findings (table 2). A potential association between a greater lesion load in brain regions associated with depressive pathology (frontal and temporal lobes and limbic system) has been demonstrated in a number of studies. ${ }^{33-38}$ For instance, increased numbers of brain lesions have been demonstrated in the frontal, ${ }^{33-36}$ right parietal and right temporal lobes ${ }^{37}{ }^{38}$ in individuals with comorbid MDD. It has thus been suggested that lesions in brain regions that are projections of the basal-limbic system produce a disruption of limbic-cortical pathways and increase the risk of MDD in individuals with MS. ${ }^{37}$ However, conversely a number of more recent studies have failed to replicate such an association between lesion load in any brain region and the presence of comorbid MDD. ${ }^{34} 39-42$

Reduced total grey matter, ${ }^{35}$ frontal lobe $^{42-44}$ and hippocampal volume ${ }^{39} 40$ have been found in individuals with MS and comorbid MDD, consistent with findings in individuals with depression without comorbid MS. ${ }^{45}$ A negative association has also recently been demonstrated between depressive symptoms and cortical surface area in frontal and parietal regions, similar to that noted in MDD without MS. ${ }^{46}$

MRI techniques evaluating white matter in individuals with MS and comorbid MDD including diffusion tensor imaging, analysed using Tract-Based Spatial Statistics and most recently connectome analysis, have demonstrated abnormalities in white matter connectivity and regional integration in several brain regions (eg, the frontal lobes and limbic regions) including the hippocampus and amygdala and subcortical regions. ${ }^{47-50}$ Based on the above neuroimaging findings, one could postulate that individuals with MS who develop MDD already have a structural susceptibility to MDD. However, given the variability of findings to date, further studies are required to more clearly elucidate the association between abnormal brain pathology and the presence of MDD in individuals with MS.

Depressive symptoms frequently go undetected or unrecognised in individuals with MS, with reports that two-thirds of individuals with active symptoms and one-third of individuals with a lifetime diagnosis of MDD had never received either a psychological or pharmacotherapeutic intervention. ${ }^{14}$ Because of the comorbidity of depressive symptoms and active symptoms of MS, caution is required with the interpretation of psychometric instruments for the measurement of MDD. However, a number of user-friendly screening tools including the Beck Fast Screen for Depression in Medically Ill Patients, the Hospital Anxiety and Depression Scale and the Beck Depression Inventory have been validated for use in MS patients with MDD. ${ }^{51-53}$ There is a paucity of well-designed randomised controlled trials (RCT) examining pharmacotherapeutic and/or psychotherapeutic options for MDD in individuals with MS. However, a number of clinical strategies have demonstrated a clinical benefit in this cohort, including most notably the selective serotonin reuptake inhibitor (SSRI) sertraline, ${ }^{17}$ the tricyclic antidepressant (TCA) desipramine ${ }^{54}$ and cognitive behavioural therapy (CBT). ${ }^{556} \mathrm{An}$ appropriate first-line pharmacological strategy for MDD is the utilisation of SSRIs, given their relatively good tolerability and relatively benign side effect profile. ${ }^{1757}$ Another putative benefit relates to evidence that SSRIs can reduce axonal degradation via induction of glycogenolysis in astrocytes, thereby increasing the energy source to neurons ${ }^{58}$ and potentially reducing the production of new enhancing lesions, ${ }^{59}$ while also increasing cAMP production initiating a reduction of inflammation and demyelination. ${ }^{60}$ Mirtazapine, due to its low propensity for sexual dysfunction and inhibition of cerebral proinflammatory cytokine production, is a viable alternative to SSRIs, although caution is required due to its sedative and weight increasing effects. ${ }^{35}$

Other pharmacotherapeutic options, although potentially associated with a greater risk of adverse effects, include low-dose TCAs (for both depression and the symptomatic relief of pain or bladder dysfunction); selective serotonin and noradrenergic reuptake inhibitors (SNRIs) (for depression and comorbid pain); ${ }^{61}$ and bupropion (for depression and reduced risk of sexual dysfunction). ${ }^{61}$ Lithium is often used in treatment-resistant MDD; however, caution is required in individuals with MS as diuresis secondary to treatment may exacerbate bladder dysfunction. An additional reason to consider lithium treatment in MS relates to studies on animal models with evidence of lithium abolishing experimental autoimmune encephalomyelitis (EAE) (the most frequently used animal model of MS) and reducing demyelination, microglia activation and leucocyte infiltration in the spinal cord of mice. ${ }^{62}$ Electro-convulsive therapy (ECT) used for intractable depressive episodes in a recent review was found to be a safe and efficacious treatment, associated with minimal neurological deterioration. ${ }^{63}$ Thus, given both the limited evidence for efficacy and significant adverse effects associated with a range of other pharmacological agents, where active enhancing lesions are not present, ECT represents a viable therapeutic option for intractable depressive episodes.

Engagement in exercise has also been to have an antidepressant effect, although limited supporting evidence is available to date ${ }^{64}$ As neuropsychiatric symptoms have been reported to fluctuate depending on current neurological status, with associations between resolution of disease activity and resolution of psychiatric symptoms, ${ }^{65}$ optimising disease-modifying agents should also be considered as a viable initial treatment option. ${ }^{2}$ Finally, agents demonstrated to have an effect on intractable fatigue may be associated with a potential mood enhancing qualities including amantadine, pemoline, modafinil and armodafanil. ${ }^{66-68}$

\section{BIPOLAR AFFECTIVE DISORDER}

The prevalence of BPAD in MS is approximately twice that in the general population, ${ }^{69}$ with rates of $0.3 \%-2.4 \%$ found,${ }^{1}$ ${ }^{70}$ although rates as high as $10 \%$ have been reported..$^{72} \mathrm{~A}$ 2014 study of patients with MS noted an OR of 15.9 for the presence of any mood disorder and 44.4 for bipolar spectrum disorders. ${ }^{73}$ This increased rate is not solely attributable to the effects of steroid treatment although up to one-third of individuals experience a corticosteroid-induced manic episode or to antidepressant-induced (hypo)manic states. ${ }^{7475}$ Other agents have also been implicated in causing episodes of (hypo)mania including baclofen, dantrolene, tizanidine and psychoactive substances. ${ }^{9}$ Drug-induced manic symptoms appear generally to be dose dependent, occur early in treatment and are usually responsive to treatment. $^{76}$ Manic symptoms (non-medication induced) may precede other neurological signs but more commonly become evident approximately 1 year after diagnosis, ${ }^{77}$ and include increased energy, pressured or rapid speech, overfamiliarity, psychomotor agitation, disinhibition, insomnia and impulsivity. ${ }^{78}$

Unlike MDD, a genetic contribution to BPAD is probable, given reports of familial clustering of both diagnoses. Furthermore, one of the genetic loci (6q 21-22 region) identified as an aetiological factor in BPAD is located within or close to the histocompatibility human leucocyte antigen system, ${ }^{79}$ within which certain haplotypes are over-represented in patients with MS. ${ }^{80}$ Other aetiological factors include psychological and adjustment processes associated with underlying personality 


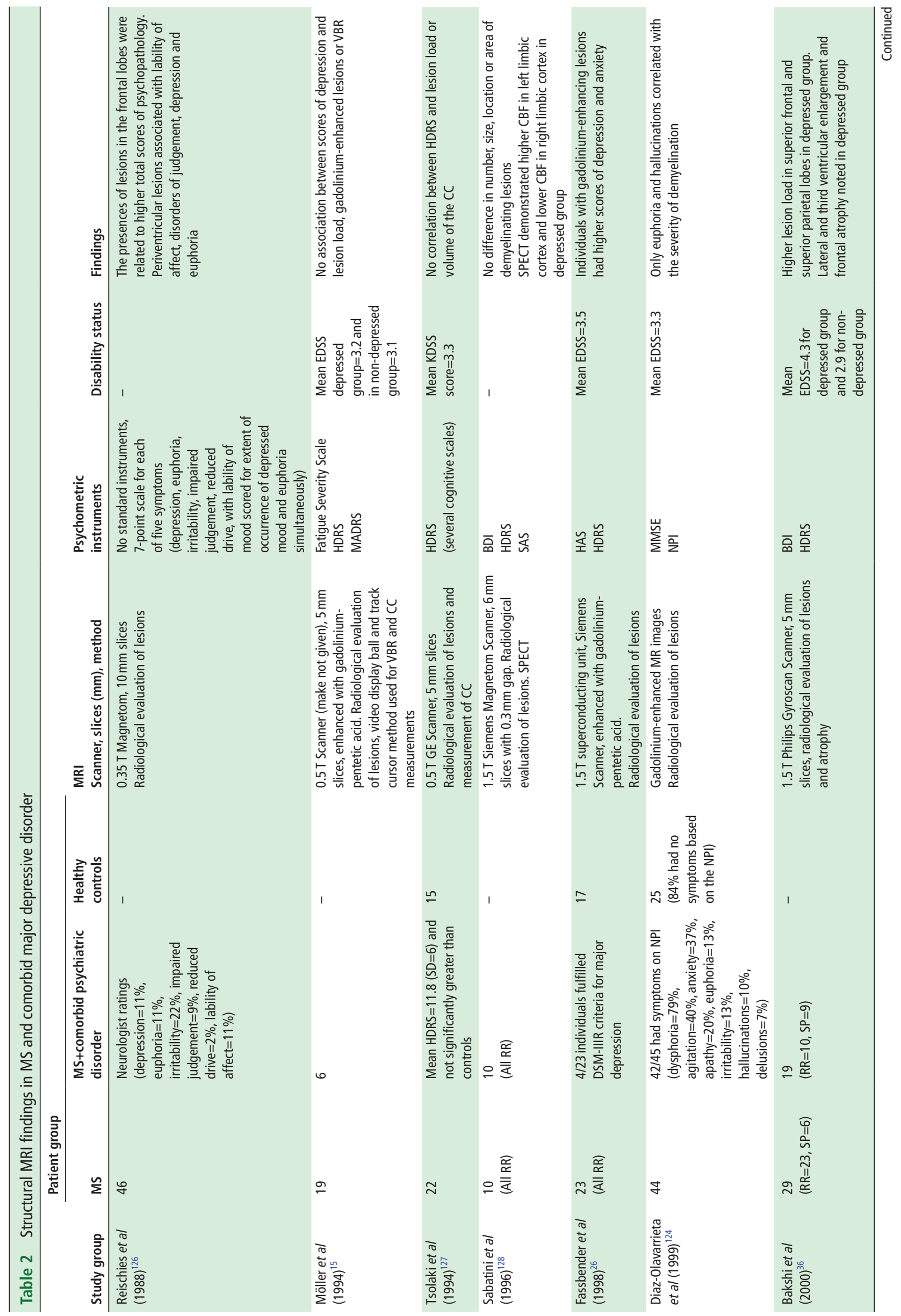




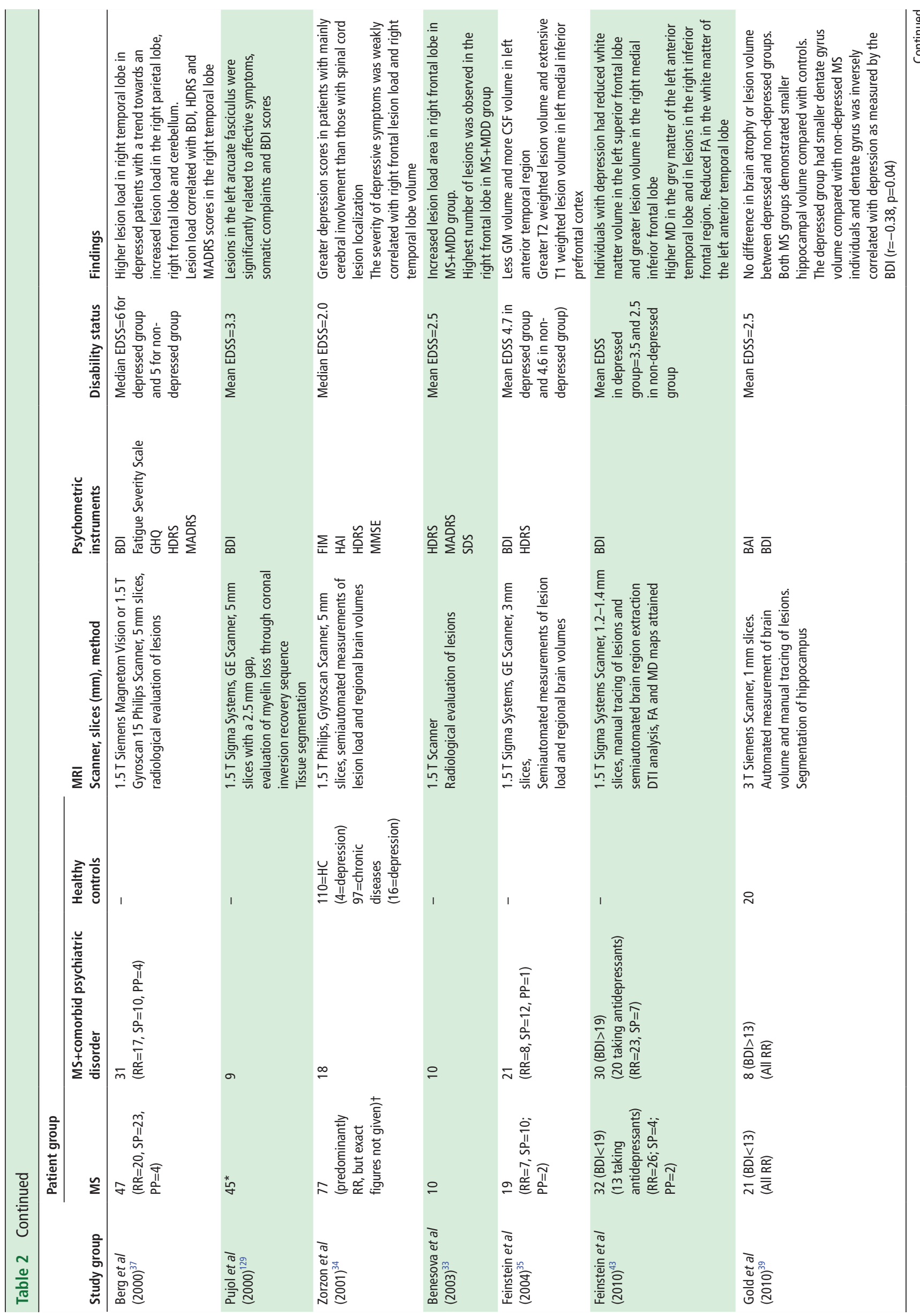




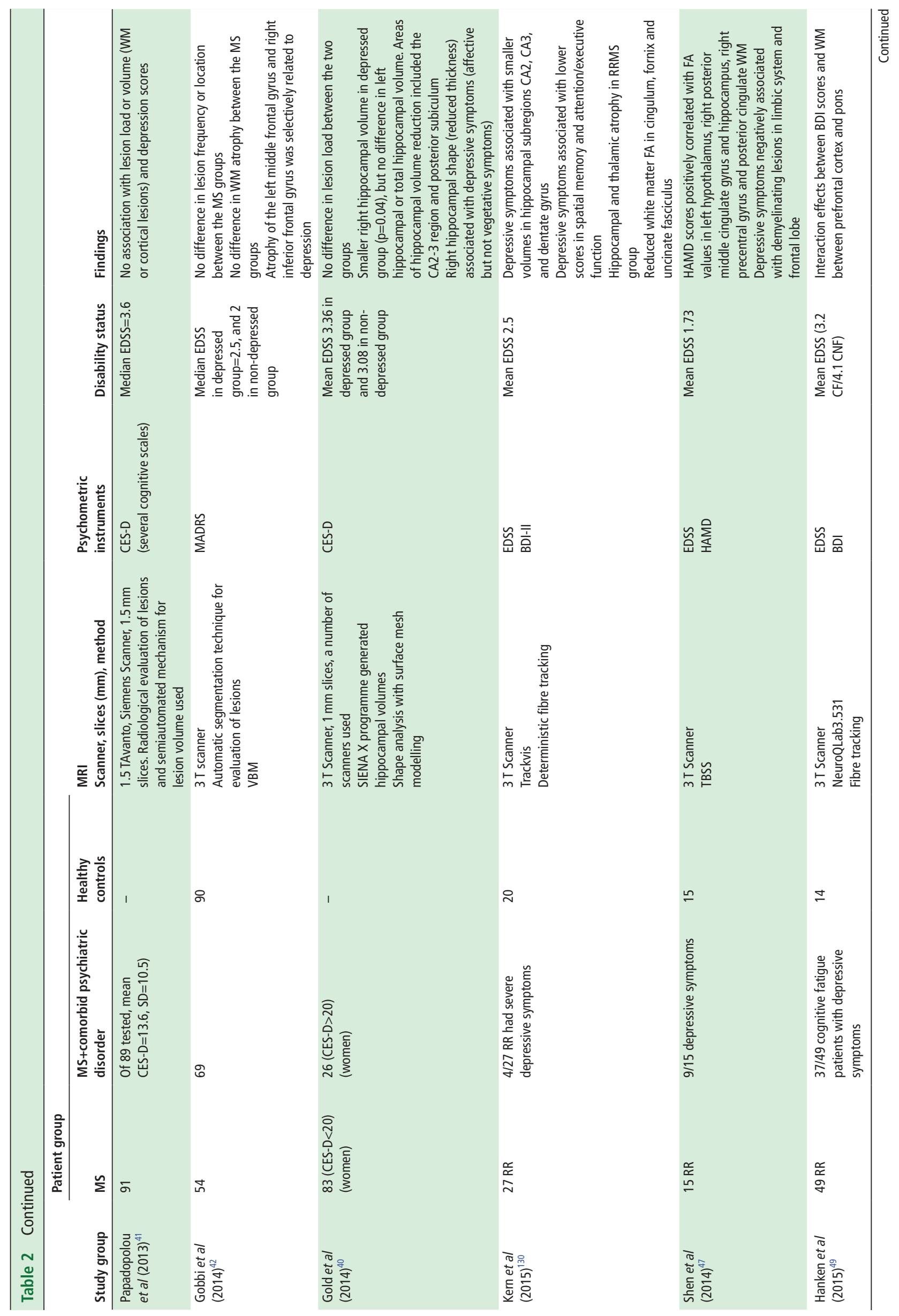




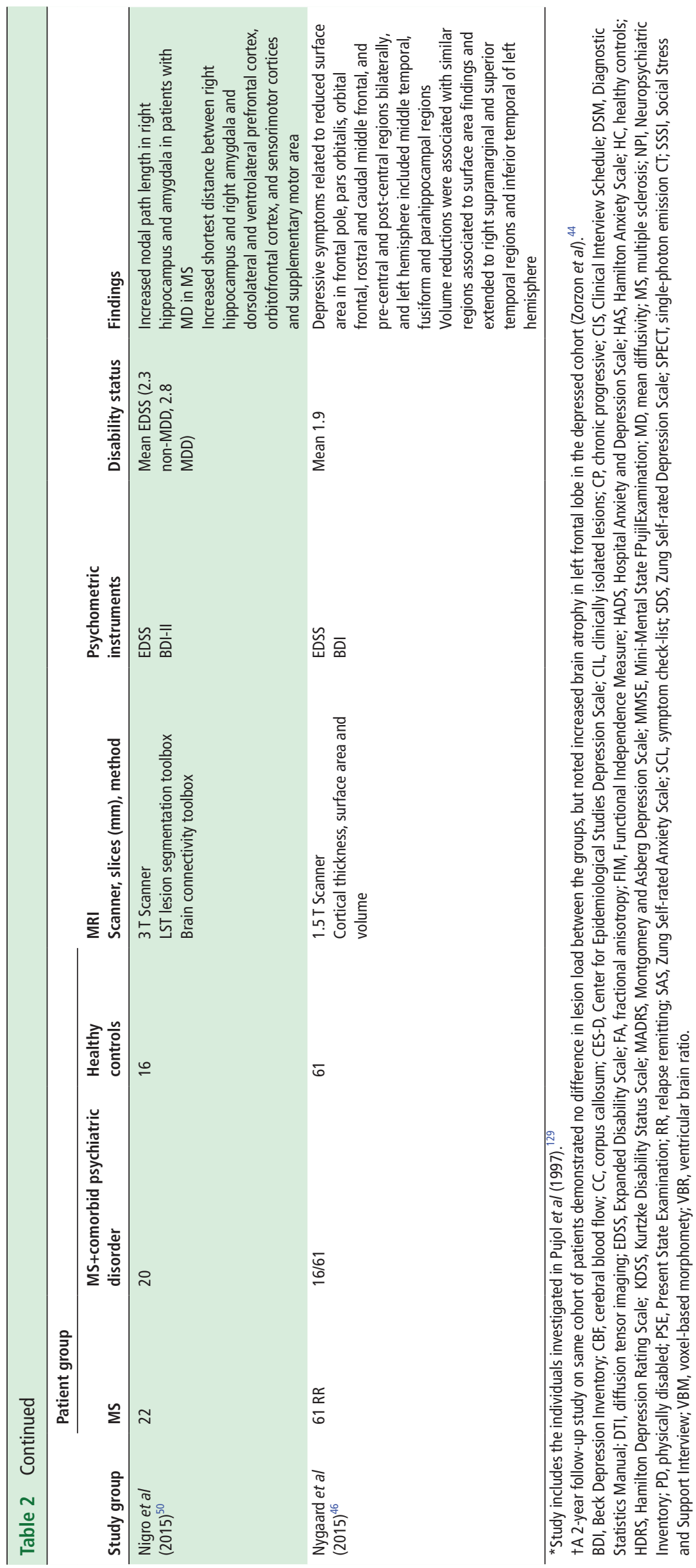


Table 3 Structural MRI findings in MS and other comorbid neuropsychiatric conditions

\begin{tabular}{|c|c|c|c|c|c|c|c|}
\hline \multirow[b]{2}{*}{ Study group } & \multicolumn{3}{|c|}{ Patient group } & \multirow{2}{*}{$\begin{array}{l}\text { MRI } \\
\text { Scanner, slices } \\
(\mathrm{mm}), \text { method }\end{array}$} & \multirow[b]{2}{*}{$\begin{array}{l}\text { Psychometric } \\
\text { instruments }\end{array}$} & \multirow[b]{2}{*}{$\begin{array}{l}\text { Disability } \\
\text { status }\end{array}$} & \multirow[b]{2}{*}{ Findings } \\
\hline & MS & $\begin{array}{l}\text { MS+comorbid } \\
\text { psychiatric disorder }\end{array}$ & $\begin{array}{l}\text { Healthy } \\
\text { controls }\end{array}$ & & & & \\
\hline $\begin{array}{l}\text { Ron and Logsdail } \\
(1989)^{83}\end{array}$ & 116 & $\begin{array}{l}50 / 116 \\
\text { (adjustment } \mathrm{D} / \mathrm{O}=22, \\
\text { depression=12 bipolar } \\
\mathrm{D} / 0=5 \text {, delusional } \\
\mathrm{D} / 0=4 \text {, atypical } \\
\text { psychosis=3, anxiety } \\
\mathrm{D} / 0=2 \text {, } \\
\text { organic disorder }=1 \text { ) }\end{array}$ & $\begin{array}{l}40 \mathrm{HC} \\
48 \mathrm{PD}(11=\text { arthritic } \\
\text { condition, } \\
37=\text { neurological } \\
\text { condition with no } \\
\text { brain involvement) } \\
\text { (depression=5, } \\
\text { adjustment } \mathrm{D} / \mathrm{O}=3 \text { ) }\end{array}$ & $\begin{array}{l}0.5 \mathrm{~T} \\
\text { superconducting } \\
\text { system Scanner, } \\
10 \mathrm{~mm} \text { slices with } \\
2 \mathrm{~mm} \text { gap, } \\
\text { radiological } \\
\text { evaluation of } \\
\text { lesions }\end{array}$ & $\begin{array}{l}\text { BDI } \\
\text { CIS } \\
\text { SSSI } \\
\text { MMSE }\end{array}$ & - & $\begin{array}{l}\text { Elation correlated with widespread } \\
\text { MRI abnormalities } \\
\text { Pathology in temporo-parietal region } \\
\text { correlated with flattened affect, } \\
\text { delusions and thought disorder }\end{array}$ \\
\hline $\begin{array}{l}\text { Feinstein et al } \\
(1992)^{84}\end{array}$ & 10 & $\begin{array}{l}10 \text { (mania with } \\
\text { psychosis) }\end{array}$ & - & $\begin{array}{l}0.5 \text { T Picker } \\
\text { Scanner, } 5 \mathrm{~mm} \\
\text { slices, } \\
\text { radiological } \\
\text { evaluation of } \\
\text { lesions }\end{array}$ & $\begin{array}{l}\text { PSE } \\
\text { SCL }\end{array}$ & $\begin{array}{l}\text { Mean } \\
\text { EDSS }=4.9\end{array}$ & $\begin{array}{l}\text { Trends reported for greater total } \\
\text { lesions in left trigone and areas } \\
\text { surrounding the third ventricle in } \\
\text { group with psychosis } \\
\text { The psychosis group had a higher } \\
\text { total lesion score and greater } \\
\text { lesions in periventricular areas, } \\
\text { predominantly around the temporal } \\
\text { horn } \\
\text { Neurological symptoms preceded } \\
\text { onset of psychosis } \\
\text { No significant correlations were } \\
\text { found between individual psychotic } \\
\text { symptoms and site of MRI lesions }\end{array}$ \\
\hline $\begin{array}{l}\text { Feinstein et al } \\
(1992)^{131}\end{array}$ & $\begin{array}{l}19 \\
(R R=12, \\
C P=7) \\
C I L=16\end{array}$ & $\begin{array}{l}3 / 35 \text { individuals had } \\
\text { comorbid psychiatric } \\
\text { disorders } \\
\text { (1=psychosis, } \\
2=\text { euphoria) }\end{array}$ & 30 & $\begin{array}{l}0.5 \text { T Picker } \\
\text { Scanner, } 5 \mathrm{~mm} \\
\text { slices } \\
\text { Radiological } \\
\text { evaluation of } \\
\text { lesions }\end{array}$ & $\begin{array}{l}\text { CIS } \\
\text { HADS } \\
\text { SSSI }\end{array}$ & $\begin{array}{l}\text { Mean } \\
\text { EDSS=3.5 }\end{array}$ & $\begin{array}{l}\text { No significant findings with } \\
\text { quantitative lesion score and } \\
\text { psychiatric status }\end{array}$ \\
\hline $\begin{array}{l}\text { Diaz-Olavarrieta } \\
\text { et al (1999) }\end{array}$ & 44 & $\begin{array}{l}42 / 45 \text { had symptoms } \\
\text { on NPI } \\
\text { (dysphoria }=79 \%, \\
\text { agitation }=40 \% \text {, } \\
\text { anxiety }=37 \%, \\
\text { apathy }=20 \%, \\
\text { euphoria }=13 \% \text {, } \\
\text { irritability }=13 \%, \\
\text { hallucinations }=10 \% \text { ) }\end{array}$ & $\begin{array}{l}25 \\
\text { ( } 84 \% \text { had no } \\
\text { symptoms based on } \\
\text { the NPI) }\end{array}$ & $\begin{array}{l}\text { Gadolinium- } \\
\text { enhanced MR } \\
\text { images } \\
\text { Radiological } \\
\text { evaluation of } \\
\text { lesions }\end{array}$ & $\begin{array}{l}\text { MMSE } \\
\text { NPI }\end{array}$ & $\begin{array}{l}\text { Mean } \\
\text { EDSS=3.3 }\end{array}$ & $\begin{array}{l}\text { Only euphoria and hallucinations } \\
\text { correlated with the severity of } \\
\text { demyelination }\end{array}$ \\
\hline $\begin{array}{l}\text { Benedict et al } \\
(2004)^{123}\end{array}$ & $\begin{array}{l}37 \\
(\mathrm{RR}=30, \\
\mathrm{SP}=7)\end{array}$ & $\begin{array}{l}\text { 31/37 had NPI } \\
\text { administered }\end{array}$ & - & $\begin{array}{l}\text { 1.5 T Philips } \\
\text { Gyroscan Scanner, } \\
5 \mathrm{~mm} \text { slices }\end{array}$ & $\mathrm{NPI}$ & $\begin{array}{l}\text { Mean } \\
\text { EDSS=2.5 }\end{array}$ & $\begin{array}{l}\text { Euphoria, depression and agitation } \\
\text { were correlated with lesion volume, } \\
\text { and euphoria was correlated with } \\
\text { global brain atrophy; however, these } \\
\text { correlations were non-significant } \\
\text { when cognitive function was } \\
\text { controlled for }\end{array}$ \\
\hline $\begin{array}{l}\text { Ghaffar et al } \\
(2008)^{112}\end{array}$ & $\begin{array}{l}14 \\
(R R=7 \\
S P=5 \\
P P=2)\end{array}$ & $\begin{array}{l}14 \\
\mathrm{PBA} \\
(\mathrm{RR}=3, \mathrm{SP}=7, \mathrm{PP}=4)\end{array}$ & - & $\begin{array}{l}\text { 1.5 T Sigma } \\
\text { Systems, } \\
\text { GE Scanner, } \\
1.2-1.4 \text { mm slices, } \\
\text { lesion analysis, } \\
\text { measurement of } \\
\text { GM, WM, CSF }\end{array}$ & - & $\begin{array}{l}\text { Mean } \\
\text { EDSS in } \\
\text { PBA }=6.0 \\
\text { and in MS } \\
\text { alone }=4.6 \\
(p=0.08)\end{array}$ & $\begin{array}{l}\text { Increased brain lesions in the } \\
\text { brainstem, left inferior parietal lobe, } \\
\text { and left and right medial and inferior } \\
\text { frontal lobes } \\
\text { No difference in brain atrophy } \\
\text { between the groups }\end{array}$ \\
\hline
\end{tabular}

BDI, Beck Depression Inventory; CIL, clinically isolated lesions; CIS, Clinical Interview Schedule; CP, chronic progressive; CSF, cerebrospinal fluid; D/O, disorder; EDSS, Expanded Disability Scale; GM, grey matter; HADS, Hospital Anxiety and Depression Scale; HC, healthy controls; HDRS, Hamilton Depression Rating Scale; MADRS, Montgomery and Asberg Depression Scale; MMSE, Mini-Mental State Examination; MS, multiple sclerosis; NPI, Neuropsychiatric Inventory; PBA, pseudobulbar affect; PSE, Present State Examination; RR, relapse remitting; SAS, Zung Self-rated Anxiety Scale; SDS, Zung Self-rated Depression Scale; SSSI, Social Stress and Support Interview; WM, white matter.

traits and coping mechanisms. ${ }^{81} 82$ To date, there have been few MRI studies examining individuals with MS and BPAD (table 3), with the limited evidence suggesting that manic episodes are more likely in patients with higher brain lesion volumes. ${ }^{83} 84$

There is also a lack of published data in relation to specific management strategies for BPAD in patients with MS. The same pharmacotherapeutic agents used in those individuals without a comorbid diagnosis of MS are often used, although caution is required due to the increased potential for adverse effects. As described above, lithium, in addition to its well-recognised mood-stabilising qualities, is also associated with potential disease-modifying effects in $\mathrm{MS},{ }^{62}$ and is associated with a reduced risk of suicide ${ }^{85}$ and may represent a viable therapeutic option, not withstanding its association with polyuria in patients with MS-associated bladder dysfunction. Caution in the use of antipsychotics is required due to their potential adverse effects 
on balance, coordination, incontinence and fatigue. Corticosteroid-induced mania can be managed with lithium, olanzapine and phenytoin, ${ }^{9}$ without the requirement for steroid discontinuation (see table 1).

\section{PSYCHOSIS}

The rate of psychosis in MS has been reported at 2\%-4\%, a rate approximately three times that found in the general population, ${ }^{86}$ with over $90 \%$ of individuals having symptoms of MS prior to the onset of psychosis. ${ }^{87}$ This increased rate of psychosis may not include an increased risk of a diagnosis of schizophrenia with a recent nationwide Swedish cohort study, noting a marginally decreased risk of schizophrenia in individuals with MS. ${ }^{88}$ Symptoms of psychosis reflect the underlying pathology of the psychotic disorder, and thus a non-affective psychotic disorder such as schizophrenia may typically be associated with persecutory delusions and auditory hallucinations, whereas an affective psychotic disorder such as mania with psychosis or a steroid-induced psychosis may be associated with grandiose or erotomanic delusion. ${ }^{89}$ The clinical presentation of symptoms has been purported to be related to MS neuropathology in periventricular white matter, and temporal and fronto-temporal regions. ${ }^{86}$ However, to date, there is a paucity of both MRI (table 2) or neuropathology studies examining this. Other aetiological factors include an inflammatory process, with some although limited data indicating that patients with schizophrenia alone have similar profiles of cytokine levels, ${ }^{90}$ psychosocial circumstances and medicinal cannabis used for individuals with MS alone. ${ }^{22}$ There is limited evidence for genetic factors playing a significant role in the development of psychotic illness. ${ }^{89}$

The treatment of psychosis is similar in individuals with MS to those without comorbid MS. However, caution is required in relation to the choice of psychotropic agent prescribed due to the potential for exacerbating adverse effects, especially extra-pyramidal side effects (EPSE). Consequently, the use of low-dose atypical (second-generation) antipsychotic agents, given their lower propensity for EPSE for the control or alleviation of psychosis, is suggested with trials indicating clinical benefit from a variety of psychotropic agents including risperidone, ${ }^{91}$ ziprasidone, ${ }^{92}$ clozapine, ${ }^{93}$ aripiprazole, ${ }^{94}$ quetiapine $^{61}$ and olanzapine, ${ }^{61}$ although clozapine is predominantly prescribed for treatment-resistant psychosis due to its association with agranulocytosis. ${ }^{61}$ An additional rationale for treatment with risperidone and quetiapine relates to their demonstrated disease-modifying characteristics in EAE mice models. ${ }^{95} 96$ There are also limited case report data demonstrating an amelioration of psychotic symptoms with disease-modifying agents. ${ }^{2}$

The choice of antipsychotic agent should consider the individual's clinical characteristics (MS and psychosis) and the potential adverse effects they may suffer secondary to the use of the psychotropic agent employed.

\section{ANXIETY DISORDERS}

Much less research has been undertaken in relation to comorbid anxiety disorders. The lifetime prevalence of anxiety disorders has been quoted to be as high as $36 \%$, with generalised anxiety disorder (19\%), panic disorder (10\%), obsessive-compulsive disorder (9\%) and social anxiety disorder (8\%) the most common disorders reported. ${ }^{97}$ A number of risk factors for anxiety disorders have been identified that potentially relate to MS, including being newly diagnosed with MS, increased MS disease activity, experiencing pain, fatigue or sleep disturbance. ${ }^{22}$ Additional risk factors noted include female gender, social isolation, a previous history of suicidal ideation, a past or present diagnosis of MDD and alcohol or psychoactive substance misuse. ${ }^{2298}$ Anxiety symptoms can present with clinical characteristics similar to those found during a relapse of MS and can often be related to the underlying disease process itself. ${ }^{99}$ The coexistence of depressive and anxiety symptoms has been found to be associated with increased rates of physical symptomatology, social dysfunction and suicidal ideation. ${ }^{100}$

In recent years, since the development of self-injectable DMTs, a phenomenon known as 'self-injection anxiety' has emerged. This anxiety can affect up to $50 \%$ of patients, and similar to simple (specific) phobias, this condition is responsive to CBT. ${ }^{101}$ Caution is required in relation to diagnosis of 'self-injection anxiety' when patients receive treatment with glatiramer acetate, given its demonstrated adverse effect profile including anxiety, dyspnoea, palpitations and tachycardia. ${ }^{102}$

There are no published RCTs specifically addressing the pharmacological treatment of anxiety disorders in MS. However, as with MDD, SSRIs should be considered first line, with venlafaxine, buspirone, pregabalin, gabapentin and beta-blockers as further options in treatment-resistant cases. ${ }^{61}$ Benzodiazepine use should be restricted to relief of acute and severe anxiety. Caution with their use is required due to their adverse effect profile of sedation and mild cognitive impairment and should not be prescribed for more than a 4-week period to avoid dependence. ${ }^{61}$ Non-pharmacological strategies including stress management and CBT should also be considered for the management of anxiety disorders in patients with MS. ${ }^{103}$ An additional benefit of treating anxiety in patients with MS may relate to a consequent reduction in the development of new MRI brain lesions, ${ }^{103}$ although this association requires replication.

\section{PSYCHOACTIVE SUBSTANCE MISUSE}

Patients with MS have been reported to have a 13.6\% lifetime prevalence of alcohol abuse or dependence. ${ }^{99}$ In addition to the known physical manifestations of alcohol abuse or dependence, other deleterious consequences may include increased depressive symptomatology, ${ }^{104}$ suicidal ideation ${ }^{27}$ and coordination difficulties. ${ }^{22}$ Brief screening tools such as the CAGE questionnaire or the Alcohol Use Disorders Identification Test may be beneficial for clinicians to adopt into routine clinical practice to help identify if alcohol misuse is present. Psychoactive substance misuse or dependence has also been noted to be present at increased rates in individuals with MS, with rates for psychoactive substance or alcohol misuse in the previous month of $19 \%$ noted. ${ }^{105}$ However, data pertaining to rates of individual psychoactive substance misuse in individuals with MS have not been reported to our knowledge. Higher rates of alcohol or psychoactive substance (excluding cannabis) use were found among younger sufferers, those still employed and patients who had less severe MS symptoms. ${ }^{105}$

Cannabis use has been reported to alleviate neurological symptoms including spasticity, pain, tremor, insomnia and bladder dysfunction, and its use has been associated with individuals with greater physical disability and dependency. ${ }^{106}$ Although clinical trials of cannabis have failed to consistently detect significant beneficial effects, ${ }^{107}$ cannabis use was detected in $33 \%$ of individuals with MS in one study. ${ }^{106}$ Certain synthetic cannabinoid oral compounds (Sativex and Nabilone) are licensed for the treatment of MS-related spasticity and neuropathic pain in some European countries. Cannabis use is however associated with a number of adverse effects including worsening cognitive function (eg, memory disturbance, poor concentration) and increasing or exacerbating depression and psychosis. 22108109 


\section{PBA AND EUPHORIA}

PBA, also known as 'pathological laughing and crying,' 'emotional incontinence,' 'pathological emotionalism' or 'involuntary emotional expression disorder,' occurs in approximately $10 \%$ of individuals with MS, to varying degrees of severity, with uncontrollable (pathological) crying more common than uncontrollable laughing. ${ }^{110}$ PBA presents more commonly in chronic disease sufferers and often in the progressive stages of MS. It is distinguishable from an affective disorder by the disassociation evident between affect and the underlying mood, resulting in incongruent emotional expression disproportionate to the underlying emotional experience and without both the expected biological symptoms of a mood disorder and the required time duration. ${ }^{76}$ The uncontrollable reaction occurs in response to non-specific stimuli, in the absence of a corresponding change in mood or loss of voluntary control of facial expression. ${ }^{9}$

PBA has traditionally been considered a disconnection syndrome resulting in the loss of cortical or brainstem inhibition of a putative centre for laughing and crying, possibly due to lesions in the cerebro-ponto-cerebellar pathways which are involved in appropriate adjustment to social and cognitive contexts. $^{22} 111$ Furthermore, a widespread increased pattern of lesions including the brainstem, and inferior frontal and parietal lobes, areas acknowledged to be involved in unconscious involvement of emotional expression, has been noted in one small $(n=14)$ MRI study. ${ }^{112}$ It has also been postulated that the monoaminergic neurotransmitter systems may be implicated, as dramatic improvements have been noted after treatments with agents acting primarily on these systems, such as SSRIs and dextromethorphan. ${ }^{113} 114$

Rating scales to detect and measure severity of PBA are available and include the self-report Center for Neurologic Study-Lability Scale. Treatment should be considered if the syndrome is associated with a high degree of social or occupational disability. ${ }^{113}$ A combination of dextromethorphan and quinidine with effects on serotonin and on sigma-1 receptors, glutamate and hepatic metabolism blocakade (quinidine) to increase bioavailability has demonstrated significant benefits for reducing emotional intensity and responses, and is licensed by both the Food and Drug Administration in the United States of America and the European Medicines Agency. ${ }^{114} 115$ Clinical benefits have been associated with SSRIs (fluoxetine, fluvoxamine, citalopram and sertraline) at low therapeutic doses with rapid improvement in symptoms including within the first week of treatment, ${ }^{113}$ and are probably the first-line treatment. Other antidepressants associated with efficacy in the treatment of PBA include SNRIs, mirtazapine, reboxetine (a noradrenaline reuptake inhibitor) and TCAs (amitriptyline, desipramine and nortriptyline). ${ }^{113} 116$ Additional agents including levodopa and amantadine (enhanced cerebral dopamine transmission), a combination of dextromethorphan and quinidine, and the mood stabiliser lamotrigine have also been associated with some clinical benefits in PBA. ${ }^{117} 118$ Care is required with the administration of these treatments given the large array of adverse effects that may occur, as detailed above.

Twenty per cent of patients with MS have been reported to suffer with emotional lability, defined as an excessive but generally brief emotional response to a minor stimulus, ${ }^{119}$ and management is similar to that used for PBA.

The presence of euphoria in MS (also known as 'euphoria sclerotica') is a well-established phenomenon and indicates a subjective state of physical well-being with a lack of concern at one's associated physical disability. ${ }^{120}$ Prevalence rates of up to $25 \%$ have been noted. ${ }^{121}$ The presence of euphoria in MS has been associated with disease progression, ${ }^{122}$ and extensive neuropathological lesions, particularly in the frontal lobe, ${ }^{77} 123$ although there is a paucity of MRI studies to date examining this phenomenon (table 3$)^{7}{ }^{7}$

Euphoria can present in a similar fashion to hypomania or mania; however, euphoria is not associated with overactivity, speech disturbance or psychotic symptoms. It is strongly associated with cognitive impairment and is often untreated due to the lack of subjective distress. ${ }^{61}$ More substantial personality changes including irritability, emotional lability and apathy can also be found in this cohort and are associated with extensive neuroanatomical abnormalities, with both the localization and extensiveness of these lesions determining the characteristics of personality change (table 2). ${ }^{124}$

\section{SUMMARY}

Neuropsychiatric signs and symptoms occur frequently in individuals with MS, either as the initial presenting complaint prior to a definitive neurological diagnosis or more commonly with disease progression. However, the pathogenesis of these comorbid conditions remains unclear, and it remains difficult to accurately elucidate if neuropsychiatric symptoms or conditions are indicators of MS illness severity. Furthermore, both the disease process and treatments of MS can adversely impact on individual's mental health. It should also be noted that a significant proportion of MS sufferers do not exhibit neuropsychiatric sequelae. This may be related in part to the 'theory of resilience,' where an individual develops an ability to maintain psychological well-being and ability to function in the face of adversity, ${ }^{22}$ or 'post-traumatic growth,' where individuals experience positive psychological changes in response to a challenging situation, ${ }^{125}$ although of course many very resilient individuals with MS exhibit significant neuropsychiatric sequelae. Optimum treatment of neuropsychiatric symptoms usually requires an interdisciplinary approach, with input from both neurological and psychiatric services. Management strategies include the optimisation of disease-modifying agents, reducing doses of iatrogenic agents where possible, initiating psychotropic agents that are least likely to exacerbate physical symptoms and the addition of appropriate psychotherapeutic interventions.

Contributors RM: study design, methodology, write-up; SO'D: study design, write-up; TC: study design, review of article; CMcD: study design, review of article; $\mathrm{BH}$ : study design, write-up, review of article.

\section{Competing interests None declared.}

Provenance and peer review Not commissioned; externally peer reviewed.

(c) Article author(s) (or their employer(s) unless otherwise stated in the text of the article) 2017. All rights reserved. No commercial use is permitted unless otherwise expressly granted.

\section{REFERENCES}

1 Marrie RA, Horwitz R, Cutter G, et al. The burden of mental comorbidity in multiple sclerosis: frequent, underdiagnosed, and undertreated. Mult Scler 2009;15:385-92.

2 Asghar-Ali AA, Taber KH, Hurley RA, et al. Pure neuropsychiatric presentation of multiple sclerosis. Am J Psychiatry 2004;161:226-31.

3 Lo Fermo S, Barone R, Patti F, et al. Outcome of psychiatric symptoms presenting at onset of multiple sclerosis: a retrospective study. Mult Scler 2010;16:742-8.

4 Patten SB, Beck CA, Williams JVA, et al. Major depression in multiple sclerosis: a population-based perspective. Neurology 2003;61:1524-7.

5 Minden SL, Schiffer RB. Affective disorders in multiple sclerosis review and recommendations for clinical research. Arch Neurol 1990;47:98-104.

6 Feinstein A. The neuropsychiatry of multiple sclerosis. Can J Psychiatry 2004;49:157-63

7 McGuigan C, Hutchinson M. Unrecognised symptoms of depression in a communitybased population with multiple sclerosis. J Neurol 2006;253:219-23.

8 Sundgren M, Maurex L, Wahlin $\AA$, et al. Cognitive impairment has a strong relation to nonsomatic symptoms of depression in relapsing-remitting multiple sclerosis. Arch Clin Neuropsychol 2013;28:144-55. 
9 Jefferies K. The neuropsychiatry of multiple sclerosis. Adv Psychiatr Treat 2006;12:214-20.

10 Sadovnick AD, Remick RA, Allen J, et al. Depression and multiple sclerosis. Neurology 1996:46:628-32.

11 Ghaffar 0, Feinstein A. The neuropsychiatry of multiple sclerosis: a review. Curr Opin Psychiatry 2007;20:278-85.

12 Sadovnick AD, Eisen K, Ebers GC, et al. Cause of death in patients attending multiple sclerosis clinics. Neurology 1991;41:1193-6.

13 Dalton EJ, Heinrichs RW. Depression in multiple sclerosis: a quantitative review of the evidence. Neuropsychology 2005;19:152-8.

14 Feinstein A. An examination of suicidal intent in patients with multiple sclerosis. Neurology 2002:59:674-8.

15 Möller A, Wiedemann G, Rohde U, et al. Correlates of cognitive impairment and depressive mood disorder in multiple sclerosis. Acta Psychiatr Scand 1994;89:117-21.

16 Noy S, Achiron A, Gabbay U, et al. A new approach to affective symptoms in relapsing-remitting multiple sclerosis. Compr Psychiatry 1995;36:390-5.

17 Scott TF, Nussbaum P, McConnell H, et al. Measurement of treatment response to sertraline in depressed multiple sclerosis patients using the carroll scale. Neurol Res 1995; 17:421-2.

18 Berg D, Supprian T, Thomae J, et al. Lesion pattern in patients with multiple sclerosis and depression. Mult Scler 2000;6:156-62.

19 Minden SL, Orav J, Reich P. Depression in multiple sclerosis. Gen Hosp Psychiatry 1987;9:426-34.

20 Mclvor GP, Riklan M, Reznikoff M. Depression in multiple sclerosis as a function of length and severity of illness, age, remissions, and perceived social support. J Clin Psychol 1984;40:1028-33.

21 Filippi M, Alberoni M, Martinelli V, et al. Influence of clinical variables on neuropsychological performance in multiple sclerosis. Eur Neurol 1994;34:324-8.

22 Chwastiak LA, Ehde DM. Psychiatric issues in multiple sclerosis. Psychiatr Clin North Am 2007:30:803-17.

23 Haussleiter IS, Brune M, Juckel G. Review: psychopathology in multiple sclerosis: diagnosis, prevalence and treatment. Ther Adv Neurol Disord 2009:2:13-29.

24 José Sá M. Psychological aspects of multiple sclerosis. Clin Neurol Neurosurg 2008;110:868-77.

25 Ribeiro SC, Tandon R, Grunhaus L, et al. The DST as a predictor of outcome in depression: a meta-analysis. Am J Psychiatry 1993;150:1618-29.

26 Fassbender K, Schmidt R, Mößner R, et al. Mood disorders and dysfunction of the hypothalamic-pituitary-adrenal axis in multiple sclerosis. Arch Neurol 1998:55:66-72.

27 Lynch SG, Kroencke DC, Denney DR. The relationship between disability and depression in multiple sclerosis: the role of uncertainty, coping, and hope. Mult Scler 2001;7:411-6

28 IFNM Multiple Sclerosis Study Group and The University of British Columbia MS/ MRI Analysis Group. Interferon beta- $1 \mathrm{~b}$ in the treatment of multiple sclerosis: final outcome of the randomized controlled trial. Neurology 1995;45:1277-8.

29 Patten SB, Metz LM. InterferonB-1a and depression in relapsing-remitting multiple sclerosis: an analysis of depression data from the PRISMS clinical trial. Mult Scler 2001;7:243-8.

30 Feinstein $\mathrm{A}$, O'Connor P, Feinstein KJ. Multiple sclerosis, interferon beta- $1 \mathrm{~b}$ and depression: a prospective investigation. J Neurol 2002;249:815-20.

31 Goeb JL, Even C, Nicolas G, et al. Psychiatric side effects of interferon-beta in multiple sclerosis. Eur Psychiatry 2006:21:186-93.

32 Rickards H. Depression in neurological disorders: parkinson's disease, multiple sclerosis, and stroke. J Neurol Neurosurg Psychiatry 2005;76:i48-52.

33 Benesova Y, Niedermayerova I, Mechl M, et al. The relation between brain MRI lesions and depressive symptoms in multiple sclerosis. Bratis/ Lek Listy 2003; 104:174-6

34 Zorzon M, de Masi R, Nasuelli D, et al. Depression and anxiety in multiple sclerosis. A clinical and MRI study in 95 subjects. J Neurol 2001;248:416-21.

35 Feinstein A, Roy P, Lobaugh N, et al. Structural brain abnormalities in multiple sclerosis patients with major depression. Neurology 2004;62:586-90.

36 Bakshi R, Czarnecki D, Shaikh ZA, et al. Brain MRI lesions and atrophy are related to depression in multiple sclerosis. Neuroreport 2000;11:1153-8.

37 Berg D, Supprian T, Thomae J, et al. Lesion pattern in patients with multiple sclerosis and depression. Multiple Sclerosis 2000;6:156-62.

38 Honer WG, Hurwitz T, Li DK, et al. Temporal lobe involvement in multiple sclerosis patients with psychiatric disorders. Arch Neurol 1987:44:187-90.

39 Gold SM, Kern KC, O'Connor MF, et al. Smaller Cornu ammonis 2-3/dentate gyrus volumes and elevated cortisol in multiple sclerosis patients with depressive symptoms. Biol Psychiatry 2010;68:553-9.

40 Gold SM, O'Connor M-F, Gill R, et al. Detection of altered hippocampal morphology in multiple sclerosis-associated depression using automated surface mesh modeling Hum Brain Mapp 2014:35:30-7.

41 Papadopoulou A, Müller-Lenke N, Naegelin Y, et al. Contribution of cortical and white matter lesions to cognitive impairment in multiple sclerosis. Mult Scler 2013;19:1290-6.
42 Gobbi C, Rocca MA, Riccitelli G, et al. Influence of the topography of brain damage on depression and fatigue in patients with multiple sclerosis. Mult Scler 2014;20:192-201.

43 Feinstein $\mathrm{A}, \mathrm{O}^{\prime}$ Connor $\mathrm{P}, \mathrm{Akbar} \mathrm{N}$, et al. Diffusion tensor imaging abnormalities in depressed multiple sclerosis patients. Mult Scler 2010;16:189-96.

44 Zorzon M, Zivadinov R, Nasuelli D, et al. Depressive symptoms and MRI changes in multiple sclerosis. Eur J Neurol 2002;9:491-6.

45 Arnone D, McKie S, Elliott R, et al. Increased amygdala responses to sad but not fearful faces in major depression: relation to mood state and pharmacological treatment. Am J Psychiatry 2012;169:841-50

46 Nygaard GO, Walhovd KB, Sowa P, et al. Cortical thickness and surface area relate to specific symptoms in early relapsing-remitting multiple sclerosis. Mult Scler 2015:21:402-14

47 Shen Y, Bai L, Gao Y, et al. Depressive symptoms in multiple sclerosis from an in vivo study with TBSS. Biomed Res Int 2014;2014:1-8.

48 Gobbi C, Rocca MA, Riccitelli G, et al. Influence of the topography of brain damage on depression and fatigue in patients with multiple sclerosis. Mult Scler 2014;20:192-201

49 Hanken $\mathrm{K}$, Eling $\mathrm{P}$, Kastrup A, et al. Integrity of hypothalamic fibers and cognitive fatigue in multiple sclerosis. Mult Scler Relat Disord 2015;4:39-46.

50 Nigro S, Passamonti L, Riccelli R, et al. Structural 'connectomic' alterations in the limbic system of multiple sclerosis patients with major depression. Mult Scler 2015;21:1003-12.

51 Beck AT, Steer RA, Brown GK. BDI - fast screen for medical patients manual. San Antonio, Texas: The Psychological Corporation, 2000.

52 Honarmand K, Feinstein A. Validation of the hospital anxiety and depression scale for use with multiple sclerosis patients. Mult Scler 2009;15:1518-24.

53 Minden SL, Feinstein A, Kalb RC, et al. Evidence-based guideline: assessment and management of psychiatric disorders in individuals with MS: report of the Guideline Development Subcommittee of the American Academy of Neurology. Neurology 2014;82:174-81.

54 Schiffer RB, Wineman NM. Antidepressant pharmacotherapy of depression associated with multiple sclerosis. Am J Psychiatry 1990;147:1493-7.

55 Mohr DC, Boudewyn AC, Goodkin DE, et al. Comparative outcomes for individual cognitive-behaviour therapy, supportive-expressive group psychotherapy, and sertraline for the treatment of depression in multiple sclerosis. J Consult Clin Psychol 2001;69:942-9.

56 Moss-Morris R, Dennison L, Landau S, et al. A randomized controlled trial of cognitive behavioural therapy (CBT) for adjusting to multiple sclerosis (the saMS Trial): Does CBT work and for whom does it work? J Consult Clin Psychol 2013;81:251-62

57 Flax JW, Gray J, Herbert J. Effects of fluoxetine on patients with multiple sclerosis. Am J Psychiatry 1991;148:1603.

58 Sijens PE, Mostert JP, Irwan R, et al. Impact of fluoxetine on the human brain in multiple sclerosis as quantified by proton magnetic resonance spectroscopy and diffusion tensor imaging. Psychiatry Res 2008;164:274-82.

59 Mostert JP, Admiraal-Behloul F, Hoogduin JM, et al. Effects of fluoxetine on disease activity in relapsing multiple sclerosis: a double-blind, placebo-controlled, exploratory study. J Neurol Neurosurg Psychiatry 2008;79:1027-31.

60 Mostert JP, Koch MW, Heerings M, et al. Therapeutic potential of fluoxetine in neurological disorders. CNS Neurosci Ther 2008;14:153-64

61 The maudsley prescribing guidelines in psychiatry. 11th Edition. United Kingdom: Wiley-Blackwell, 2012

62 Chiu C-T, Chuang D-M. Molecular actions and therapeutic potential of lithium in preclinical and clinical studies of CNS disorders. Pharmacol Ther 2010;128:281-304.

63 Steen K, Narang P, Lippmann S. Electroconvulsive therapy in multiple sclerosis. Innov Clin Neurosci 2015:12:28-30.

64 Dalgas $U$, Stenager $E$, Sloth $M$, et al. The effect of exercise on depressive symptoms in multiple sclerosis based on a meta-analysis and critical review of the literature. Eur J Neurol 2015;22:443-e34.

65 Kroencke DC, Denney DR, Lynch SG. Depression during exacerbations in multiple sclerosis: the importance of uncertainty. Mult Scler 2001;7:237-42.

66 Krupp LB, Coyle PK, Doscher C, et al. Fatigue therapy in multiple sclerosis: results of a double-blind, randomized, parallel trial of amantadine, pemoline, and placebo. Neurology 1995;45:1956-61.

67 Wingerchuk DM, Benarroch EE, O'Brien PC, et al. A randomized controlled crossover trial of aspirin for fatigue in multiple sclerosis. Neurology 2005;64:1267-9.

68 Calabrese JR, Frye MA, Yang R, et al. Efficacy and safety of adjunctive armodafanil in adults with major depressive episodes associated with bipolar 1 disorder: a randomized, double-blind, placebo-controlled multicenter trial. J Clin Psychaitry 2014;75:1054-61

69 Schiffer RB, Wineman NM, Weitkamp LR. Association between bipolar affective disorder and multiple sclerosis. Am J Psychiatry 1986;143:94-5.

70 Edwards LJ, Constantinescu CS. A prospective study of conditions associated with multiple sclerosis in a cohort of 658 consecutive outpatients attending a multiple sclerosis clinic. Mult Scler 2004;10:575-81.

71 Joffe RT, Lippert GP, Gray TA, et al. Mood disorder and multiple sclerosis. Arch Neurol $1987 ; 44: 376-8$ 
72 Minden SL. Mood disorders in multiple sclerosis: diagnosis and treatment. J Neurovirol 2000;6(Suppl 2):S160-7.

73 Carta MG, Moro MF, Lorefice L, et al. The risk of bipolar disorders in multiple sclerosis. J Affect Disord 2014;155:255-60.

74 Bhangle SD, Kramer N, Rosenstein ED. Corticosteroid-induced neuropsychiatric disorders: review and contrast with neuropsychiatric lupus. Rheumatol Int 2013;33:1923-32.

75 Baldessarini RJ, Faedda GL, Offidani E, et al. Antidepressant-associated moodswitching and transition from unipolar major depression to bipolar disorder: a review. J Affect Disord 2013;148:129-35.

76 lacovides A, Andreoulakis E. Bipolar disorder and resembling special psychopathological manifestations in multiple sclerosis: a review. Curr Opin Psychiatry 2011;24:336-40.

77 Clarke T, Wadhwa U, Leroi I. Psychotic depression: an atypical initial presentation of multiple sclerosis. Psychosomatics 1998;39:72-5.

78 Feinstein A. Neuropsychiatric syndromes associated with multiple sclerosis. J Neurol 2007:254:1173-6.

79 Nurnberger JI, Foroud T, Eckstein G, et al. Chromosome 6 workshop report. Am J Med Genet 1999:88:233-8.

$80 \mathrm{Xu}$ C, Dai Y, Lorentzen JC, et al. Linkage analysis in multiple sclerosis of chromosomal regions syntenic to experimental autoimmune disease loci. Eur J Hum Genet 2001:9:458-63.

81 McCabe MP. Mood and self-esteem of persons with multiple sclerosis following an exacerbation. J Psychosom Res 2005:59:161-6.

82 Johnson SK, DeLuca J, Natelson BH. Personality dimensions in the chronic fatigue syndrome: a comparison with multiple sclerosis and depression. J Psychiatr Res 1996;30:9-20.

83 Ron MA, Logsdail SJ. Psychiatric morbidity in multiple sclerosis: a clinical and MRI study. Psychol Med 1989;19:887-95.

84 Feinstein A, du Boulay G, Ron MA. Psychotic illness in multiple sclerosis. A clinical and magnetic resonance imaging study. Br J Psychiatry 1992;161:680-5.

85 Zalsman G, Hawton K, Wasserman D, et al. Suicide prevention strategies revisited: 10-year systematic review. Lancet Psychiatry 2016;3:646-59.

86 Patten SB, Svenson LW, Metz LM. Psychotic disorders in MS: population-based evidence of an association. Neurology 2005;65:1123-5.

87 Skegg K, Corwin PA, Skegg DCG. How often is multiple sclerosis mistaken for a psychiatric disorder? Psychol Med 1988;18:733-6.

88 Johansson V, Lundholm C, Hillert J, et al. Multiple sclerosis and psychiatric disorders: comorbidity and sibling risk in a nationwide swedish cohort. Mult Scler 2014;20:1881-91.

89 Kosmidis MH, Giannakou M, Messinis L, et al. Psychotic features associated with multiple sclerosis. Int Rev Psychiatry 2010;22:55-66.

90 Clerici M, Saresella M, Trabattoni D, et al. Single-cell analysis of cytokine production shows different immune profiles in multiple sclerosis patients with active or quiescent disease. J Neuroimmuno/ 2001;121:88-101.

91 Furmaga KM, DeLeon O, Sinha S. Risperidone response in refractory psychosis due to a general medical condition. J Neuropsychiatry Clin Neurosci 1995;7:417.

92 Davids E, Hartwig U, Gastpar M. Antipsychotic treatment of psychosis associated with multiple sclerosis. Prog Neuropsychopharmacol Biol Psychiatry 2004;28:743-4.

93 Chacko RC, Hurley RA, Harper RG, et al. Clozapine for acute and maintenance treatment of psychosis in Parkinson's disease. J Neuropsychiatry Clin Neurosci 1995:7:471-5

94 Reimer J, Aderhold V, Lambert M, et al. Manifestation of multiple sclerosis with paranoid-hallucinatory psychosis. J Neurol 2006;253:531-2.

95 O'Sullivan D, Green L, Stone S, et al. Treatment with the antipsychotic agent, risperidone, reduces disease severity in experimental autoimmune encephalomyelitis. PLoS One 2014;9:e104430.

96 Zhornitsky S, Wee Yong V, Koch MW, et al. Quetiapine fumarate for the treatment of multiple sclerosis: focus on myelin repair. CNS Neurosci Ther 2013;19:737-44.

97 Korostil M, Feinstein A. Anxiety disorders and their clinical correlates in multiple sclerosis patients. Mult Scler 2007;13:67-72.

98 Janssens AC, Buljevac D, van Doorn PA, et al. Prediction of anxiety and distress following diagnosis of multiple sclerosis: a two-year longitudinal study. Mult Scler 2006;12:794-801.

99 Ó Donnchadha S, Burke T, Bramham J, et al. Symptom overlap in anxiety and multiple sclerosis. Mult Scler 2013;19:1349-54.

100 Feinstein A, O'Connor P, Gray T, et al. The effects of anxiety on psychiatric morbidity in patients with multiple sclerosis. Mult Scler 1999:5:323-6.

101 Mohr DC, Cox D, Epstein L, et al. Teaching patients to self-inject: pilot study of a treatment for injection anxiety and phobia in multiple sclerosis patients prescribed injectable medications. J Behav Ther Exp Psychiatry 2002;33:39-47.

102 Caporro M, Disanto G, Gobbi C, et al. Two decades of subcutaneous glatiramer acetate injection: current role of the standard dose, and new high-dose low- frequency glatiramer acetate in relapsing-remitting multiple sclerosis treatment. Patient Prefer Adherence 2014:8:1123-34.

103 Janssens AC, Buljevac D, van Doorn PA, et al. Prediction of anxiety and distress following diagnosis of multiple sclerosis: a two-year longitudinal study. Mult Scler 2006; 12:794-801.

104 Spitzer RL, Gibbon M. Structured clinical interview for Axis I DSM-IV disorders patient edition. SCID Version 2.0. New York: State Psychiatric Institute, 1994.

105 Choy W, Gerstein DR, Ghadialy R, et al; National household survey on drug abuse: main findings 1992. Rockville MD: Substance abuse and mental health services administration, 1995.

106 Chong MS, Wolff K, Wise K, et al. Cannabis use in patients with multiple sclerosis. Mult Scler 2006;12:646-51.

107 Zajicek J, Fox P, Sanders H, et al. Cannabinoids for treatment of spasticity and other symptoms related to multiple sclerosis (CAMS study): multicenter randomized placebo-controlled trial. Lancet 2003:362:1517-26.

108 Feinstein A, Feinstein K, Gray T, et al. Prevalence and neurobehavioral correlates of pathological laughing and crying in multiple sclerosis. Arch Neurol 1997:54:1116-21.

109 Yadav V, Bever C, Bowen J, et al. Summary of evidence-based guideline: complementary and alternative medicine in multiple sclerosis: report of the Guideline Development Subcommittee of the American Academy of Neurology. Neurology 2014:82:1083-92.

110 Chohan H, Greenfield AL, Yadav V, et al. Use of cannabinoids for spasticity and pain management in MS. Curr Treat Options Neuro/ 2016;18:1.

111 Parvizi J, Anderson SW, Martin CO, et al. Pathological laughter and crying: a link to the cerebellum. Brain 2001;124:1708-19.

112 Ghaffar O, Chamelian L, Feinstein A. Neuroanatomy of pseudobulbar affect: a quantitative MRI study in multiple sclerosis. J Neurol 2008;255:406-12.

113 Wortzel HS, Oster TJ, Anderson CA, et al. Pathological laughing and crying: epidemiology, pathophysiology and treatment. CNS Drugs 2008;22:531-45.

114 Stahl SM. Dextromethorphan-quinidine-responsive pseudobulbar affect (PBA) psychopharmacological model for wide-ranging disorders of emotional expression? CNS Spectr 2016:21:419-23.

115 Pioro EP. Review of dextromethorphan 20 mg/Quinidine $10 \mathrm{mg}$ (NUEDEXTA(®)) for Pseudobulbar Affect. Neurol Ther 2014;3:15-28.

116 Moore SR, Gresham LS, Bromberg MB, et al. A self report measure of affective lability. J Neurol Neurosurg Psychiatry 1997:63:89-93.

117 Paparrigopoulos T, Ferentinos P, Kouzoupis A, et al. The neuropsychiatry of multiple sclerosis: focus on disorders of mood, affect and behaviour. Int Rev Psychiatry 2010;22:14-21.

118 Ghaffar O, Feinstein A. The neuropsychiatry of multiple sclerosis: a review. Curr Opin Psychiatry 2007;20:278-85.

119 Feinstein A. The clinical neuropsychiatry of multiple sclerosis. Cambridge, United Kingdom: Cambridge University Press, 1999.

120 Cottrell SS, Wilson SA. The affective symptomatology of disseminated sclerosis: a study of 100 cases. J Neurol Psychopath 1926;7:1-30.

121 Rabins PV. Euphoria in multiple sclerosis. Neurobehavioural aspects of multiple sclerosis. New York: Oxford University Press, 1990:180-5.

122 Benedict RH, Bobholz JH. Multiple sclerosis. Semin Neurol 2007;27:078-85.

123 Benedict RHB, Carone DA, Bakshi R. Correlating brain atrophy with cognitive dysfunction, mood disturbances, and personality disorder in multiple sclerosis. J Neuroimaging 2004;14:36-45.

124 Diaz-Olavarrieta C, Cummings JL, Velazquez J, et al. Neuropsychiatric manifestations of multiple sclerosis. J Neuropsychiatry Clin Neurosci 1999:11:51-7.

125 Tedeschi RG, Calhoun LG. The posttraumatic growth inventory: measuring the positive legacy of trauma. J Trauma Stress 1996;9:455-71.

126 Reischies FM, Baum K, Bräu H, et al. Cerebral magnetic resonance imaging findings in multiple sclerosis. relation to disturbance of affect, drive, and cognition. Arch Neurol 1988;45:1114-6.

127 Tsolaki M, Drevelegas A, Karachristianou S, et al. Correlation of dementia, neuropsychological and MRI findings in multiple sclerosis. Dement Geriatr Cogn Disord 1994:5:48-52.

128 Sabatini U, Pozzilli C, Pantano P, et al. Involvement of the limbic system in multiple sclerosis patients with depressive disorders. Biol Psychiatry 1996;39:970-5.

129 Pujol J, Bello J, Deus J, et al. Beck depression inventory factors related to demyelinating lesions of the left arcuate fasciculus region. Psychiatry Res 2000:99:151-9.

130 Kern KC, Gold SM, Lee B, et al. Thalamic-hippocampal-prefrontal disruption in relapsing-remitting multiple sclerosis. Neuroimage Clin 2015;8:440-7.

131 Feinstein A, Kartsounis LD, Miller DH, et al. Clinically isolated lesions of the type seen in multiple sclerosis: a cognitive, psychiatric, and MRI follow up study. J Neurol Neurosurg Psychiatry 1992;55:869-76. 